\title{
Sequential Organ Failure Assessment [SOFA] Score in the Pediatric Intensive Care Unit
}

A.S.Sayed, O.M.Abd El Haie and A.A.Shehata

Pediatrics Dept, Faculty of Medicine, Benha Univ., Benha, Egypt

E-Mail:aboashraf.ashraf0100@gmail.com

\begin{abstract}
Estimation of disease severity and probability of death are important elements in determining the prognosis of patients in ICU. It has been a consistent observation that in pediatric intensive care unit children usually experience multiple organ dysfunction syndromes [MODS]. Sequential organ failure assessment [SOFA] score is based on MODS and help in predicting outcome in critically ill children The aim of this work was to test the value of a pediatric version of SOFA score [pSOFA] in a cohort of critically ill children admitted into the pediatric intensive care unit.

Our study was conducted at the pediatric intensive care unit, Pediatric Hospital, Benha University and Benha children hospital. Fifty critically ill patients were included in our study. All patients were subjected to medical history, clinical examination and laboratory investigations. Calculation of pSOFA score was measured.

sex was almost equal among the studied cases. Regarding etiology of the studied cases. Septic shock and respiratory failure were the most frequent etiologies. Mean value of $\mathrm{Hb}$ was low and a high significant decrease in platelets count among cases.overall mortality rate was $28 \%$.GCS was significantly lower among died cases than among lived cases.The value of pSOFA score was significantly higher among non-survived than survived cases [13.5,5.5 respectively]. Total pSOFA $\geq 9.0$ had highest diagnostic characteristics in prediction of death.

Pediatric SOFA score [pSOFA] score can be used as a reliable prognostic predictor of mortality among PICU patients.
\end{abstract}

Key words: Sequential organ failure assessment score, Pediatric intensive care unit- prognosis.

\section{Introduction:}

Estimation about ailment seriousness Also likelihood about demise need aid essential components to figuring out those prognosis about patients in frigid. It need been a steady perception that over pediatric seriousness know youngsters as a rule knowledge numerous organ brokenness syndromes [MODS]. Over frigid mortal sin correlates for number for falling flat organ framework Also level from claiming brokenness inside whatever provided for organ framework. [21].

The improvement from claiming progressive physiological brokenness remote starting with those site of elementary malady termed Likewise various organ brokenness syndrome gives the idea on create for An synchronous way, not clinched alongside An consecutive way and a significant part prior for Youngsters [6]. Twenty five percent of the kids admitted with PICU need mods and that those mortal sin connected with it is up to 50. Previously, fact, $97 \%$ will $100 \%$ of the passings for PICUs need been identified with mods [20].

Different organ brokenness syndrome [MODS], formerly known as different organ disappointment [MOF] or multisystem organ disappointment $[\mathrm{MSOF}]$, is those vicinity about modified organ capacity in acutely sick patients such-and-such homeostasis can't make administered without mediation. It normally includes two or that's only the tip of the iceberg organ frameworks [8].

Couch may be In light of mods Furthermore assistance Previously, foreseeing Conclusion in critically sick kids [6].
Seriousness of-illness scoring frameworks bring been generally utilized within pediatric emergency unit units.

[PICUs] with quantify tolerant results. These scoring frameworks might be utilized to interior What's more outer benchmarking should assess seriousness from claiming illness, proper monitoring, best possible oversaw economy What's more crew guiding. [18]. Couch framework might have been made in An agreement gathering from claiming european social order for emergency unit medication done 1994 and reconsidered in1996. Couch framework will be An six organ dysfunction/failure score measuring various organ brokenness Every day. Each organ may be graded 0 [normal] will 4 [most abnormal] giving work to a Every day aggregate score for $0-24$ focuses. The couch score may be not difficult Similarly as variables measured would effortlessly accessible Furthermore routinely measured Previously, frigid yet the PELOD score which may be that's only the tip of the iceberg cumbersome, employments a greater amount variables [8].

Those point for this fill in might have been on test the worth of a pediatric rendition for couch score [pSOFA] done a associate of critically sick kids admitted under the pediatric seriousness.

\section{Patients and methods}

\subsection{Technical design}

Our study was conducted at the pediatric intensive care unit, Pediatric Hospital, Benha University and Benha children hospital. Fifty critically ill patients were included in our study. 


\subsubsection{Inclusion criteria}

Any Critically ill patient admitted in PICU like [sepsis, ARDS, heart failure, shock, polytraumatised patient, DKA etc.]Age of the patients under 18 years old.

\subsubsection{Exclusion criteria}

Patients with Age above 18 years old.

\subsubsection{Ethical considerations}

Written informed consent were taken from adult patients or their parents before enrollment in this study and after approval of the Local Ethical Committee, Benha University.

\subsection{Methods}

\subsubsection{All patients were subjected to thorough} medical history laying stress on:

- Demographic data [name, age and sex].

- Age of onset and disease duration.

- Hospital admissions and history of complications.

- Family, nutritional and-drug-history

- Outcome-of-the-disease.

\subsubsection{Full clinical examination}

- General examination [weight and height standard deviation and body mass index percentile].

- Systemic examination [CNS, chest, heart and abdomen].

- The vital signs and Oxygen saturation was monitored.

2.2.3 Laboratory investigations

- Complete blood picture

- Arterial Blood Gases

- serum electrolytes

- liver function tests

- Kidney function tests.

- Sepsis screening for suspected sepsis. a. Total leukocytic count

b. Neutrophil count

c. I:T ratio

d. Blood culture

e. Erythrocytic sedimentation rate

f. C-Reactive Protien

g. platelet count

- Specific investigations according to the situations e.g. chest x ray, brain CT, Echocardiography.

- Calculation of pSOFA score

\begin{tabular}{|c|c|c|}
\hline Measure & Finding & Points \\
\hline Pao2 to Fio2 ratio & $\begin{array}{ll} & \varepsilon \cdots \mathrm{mm} \mathrm{Hg} \\
- & 300-399 \mathrm{~mm} \mathrm{Hg} \\
\text { - } & 200-299 \mathrm{~mm} \mathrm{Hg} \\
- & 100-199 \mathrm{mmHg} \text { and mechanically ventilated } \\
\text { - } & <100 \mathrm{~mm} \mathrm{Hg} \text { and mechanically ventilated }\end{array}$ & $\begin{array}{l}0 \\
1 \\
2 \\
3 \\
4\end{array}$ \\
\hline Platelet count & $\begin{array}{l}\text { - } \quad>150,000 \text { per microliter of blood } \\
\text { - } \\
\text { - } \\
\text { - } \\
\text { - } \\
\text { - }\end{array}$ & $\begin{array}{l}0 \\
1 \\
2 \\
3 \\
4\end{array}$ \\
\hline Serum & - $\quad<1.2 \mathrm{mg} / \mathrm{dl}$ & 0 \\
\hline Bilirubin & $\begin{array}{ll}\text { - } & 1.2-1.9 \mathrm{mg} / \mathrm{dl} \\
\text { - } & 2-5.9 \mathrm{mg} / \mathrm{dl} \\
\text { - } & 6-11.9 \mathrm{mg} / \mathrm{dl} \\
& >12 \mathrm{mg} / \mathrm{dl}\end{array}$ & $\begin{array}{l}1 \\
2 \\
3 \\
4\end{array}$ \\
\hline Hypotention & $\begin{array}{ll}\text { - } & \text { MAP }>70 \\
\text { - } & \text { MAP }<70, \text { no pressor agents used } \\
\text { - } & \text { dopamine } \leq 5 \mu \mathrm{g} / \mathrm{kg} / \mathrm{min} \text { or dobutamine [any dose] } \\
\text { - } & \text { dopamine }>5 \mu \mathrm{g} / \mathrm{kg} / \mathrm{min} \\
\text { OR norepinephrine } \leq 0.1 \mu \mathrm{g} / \mathrm{kg} / \mathrm{mi} & \text { OR epinephrine } \leq 0.1 \mu \mathrm{g} / \mathrm{kg} / \mathrm{min} \\
\text { - } & \begin{array}{l}\text { dopamine }>15 \mu \mathrm{g} / \mathrm{kg} / \mathrm{min} \quad \text { OR } \\
\text { norepinephrine }>0.1 \mu \mathrm{g} / \mathrm{kg} / \mathrm{min}\end{array} \\
\end{array}$ & $\begin{array}{l}0 \\
1 \\
2 \\
3 \\
4\end{array}$ \\
\hline Glasgow coma scale & $\begin{array}{ll}\cdot & 15 \\
\cdot & 13-14 \\
\cdot & 10-12 \\
\cdot & 6-9 \\
\cdot & <6\end{array}$ & $\begin{array}{l}0 \\
1 \\
2 \\
3 \\
4\end{array}$ \\
\hline $\begin{array}{l}\text { Creatinine } \quad[\mathrm{mg} / \mathrm{dl}] \\
{[\mu \mathrm{mol} / \mathrm{L}] \quad[\text { or } \text { urine }} \\
\text { output }]\end{array}$ & $\begin{array}{ll} & <1.2[<110] \\
- & 1.2-1.9[110-170] \\
\text { - } & 2.0-3.4[171-299] \\
\text { - } & 3.5-4.9[300-440][\text { or }<500 \mathrm{ml} / \mathrm{d}] \\
\text { - } & >5.0[>440][\text { or }<200 \mathrm{ml} / \mathrm{d}]\end{array}$ & $\begin{array}{l}0 \\
1 \\
2 \\
3 \\
4\end{array}$ \\
\hline
\end{tabular}

- Close follow up of the patients to determine the occurrence of complications.

\subsection{Statistical analysis}

The collected data were tabulated and analyzed 
using SPSS version 16 software [Spss Inc, Chicago, ILL Company]. Categorical data were presented as number and percentages. Chi square test $\left[\mathrm{X}^{2}\right]$, or Fisher's exact test [FET] were used to analyze categorical variables. Quantitative data were tested for normality using Kolomogrov Smirnove test assuming normality at $\mathrm{P}>0.05$. Quantitative data were expressed as mean \pm standard deviation, median and range. Student "t" test was used to analyze normally distributed variables among 2 independent groups, or Man Whitney U test for nonparametric ones. Difference among 3 independent means was analyzed using ANOVA for parametric variables or Kruskal Wallis test [KWT] for nonparametric ones. Spearman's correlation coefficient [ rho ] was used to assess correlation between non parametric variables. ROC curve was used to detect cutoff values with optimum sensitivity and specificity. The accepted level of significance in this work was stated at 0.05 $[\mathrm{P}<0.05$ was considered significant].

\section{Results}

Fig [1] show that: Demographic characteristics of the studied cases. Sex was almost equal among the studied cases.

Fig [2] show that: Possible etiology of the studied cases. Septic shock and respiratory failure were the most frequent etiologies.

Table [1] show that: Death was in more than quarter of the studied cases.

Table [2] show that: pSOFA scores were significantly higher among died cases than among lived cases.

Table [3] and fig [3]: GCS, hepatic score, neurologic score and total pSOFA score had significant high diagnostic performance in predicting death. Creatinine, total bilirubin, respiratory score, cardiovascular score and renal score had significant moderate diagnostic performance in predicting death. PaO2:FiO2, platelets, coagulation had significant low diagnostic performance in predicting death. Other variables had no significant diagnostic performance in predicting death.

Table [4]: Total pSOFA $\geq 9.0$ had highest diagnostic characteristics in prediction of death.

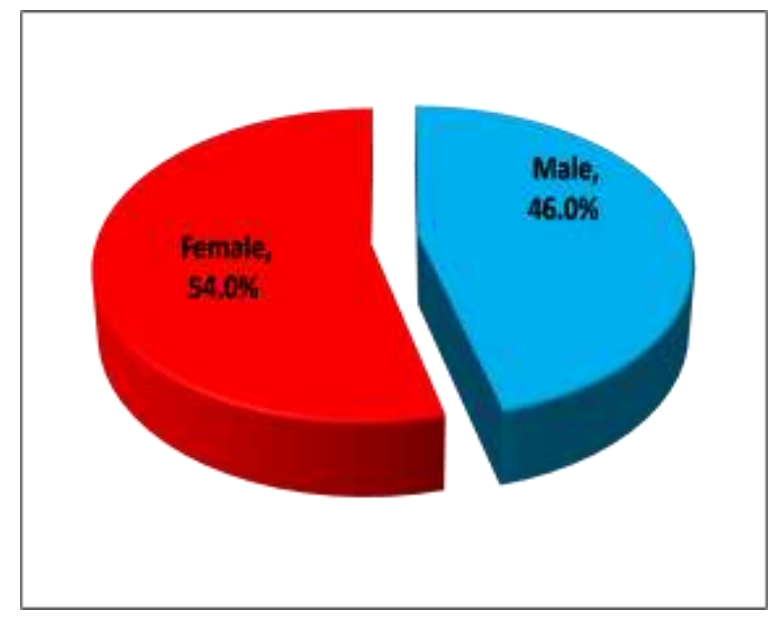

Fig [1] Sex distribution of the studied cases

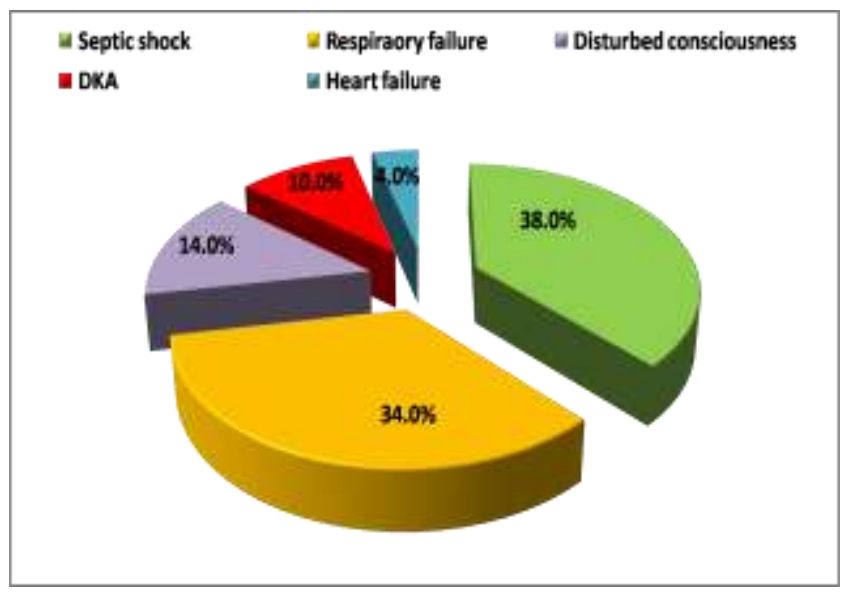

Fig [2] Possible etiology among of the studied cases

Table [1] Outcome among the studied cases 


\begin{tabular}{lccc}
\hline & Outcome & N & \% \\
\hline Died & 14 & 28.0 \\
Lived & 36 & 72.0 \\
\hline
\end{tabular}

Table [2] Comparison according to mortality regarding pSOFA scores

\begin{tabular}{lccc}
\hline Scores & $\begin{array}{c}\text { Died } \\
{[\mathbf{N = 1 4}]}\end{array}$ & $\begin{array}{c}\text { Lived } \\
{[\mathbf{N}=\mathbf{3 6}]}\end{array}$ & $\mathbf{p}$ \\
\hline Respiratory & $2.0[2.0-3.0[$ & $1.0[1.0-2.0[$ & $\#<\mathbf{0 . 0 0 1 *}$ \\
Coagulation & $1.5[0.8-2.3[$ & $0.0[0.0-1.0[$ & $\#<\mathbf{0 . 0 0 1}$ \\
Hepatic & $2.5[2.0-3.0[$ & $1.0[0.0-1.0[$ & $\#<\mathbf{0 . 0 0 1}$ \\
Cardiovascular & $2.0[2.0-2.3[$ & $1.0[1.0-1.0[$ & $\#<\mathbf{0 . 0 0 1}$ \\
Neurologic & $3.0[2.0-4.0[$ & $1.0[0.0-1.0[$ & $\#<\mathbf{0 . 0 0 1}$ \\
Renal & $2.0[2.0-3.0[$ & $1.0[0.0-2.0[$ & $\#<\mathbf{0 . 0 0 1}$ \\
Total & $13.5[10.0-16.3[$ & $5.5[3.0-7.8[$ & $\#<\mathbf{0 . 0 0 1}$ \\
\hline
\end{tabular}

Table [3] Diagnostic performance of in prediction of death

\begin{tabular}{lccccc}
\hline \multicolumn{1}{c}{ Factors } & AUC & SE & P & 95\% CI & Cut off \\
\hline Age [years[ & 0.590 & 0.088 & 0.326 & $0.419-0.762$ & -- \\
Weight percen. & 0.512 & 0.096 & 0.897 & $0.324-0.700$ & -- \\
Height percen. & 0.562 & 0.088 & 0.503 & $0.388-0.735$ & -- \\
BMI percen. & 0.588 & 0.089 & 0.336 & $0.413-0.763$ & -- \\
GCS & 0.914 & 0.039 & $<0.001^{*}$ & $0.838-0.990$ & $\leq 13.0$ \\
PaO $_{2}:$ FiO & \\
MAP & 0.787 & 0.086 & $0.002^{*}$ & $0.618-0.956$ & -- \\
Hemoglobin & 0.606 & 0.098 & 0.248 & $0.414-0.798$ & -- \\
Platelets & 0.573 & 0.101 & 0.424 & $0.375-0.772$ & - \\
TLC & 0.797 & 0.072 & $0.001^{*}$ & $0.655-0.938$ & - \\
Creatinine & 0.637 & 0.102 & 0.136 & $0.437-0.837$ & -- \\
Total bilirubin & 0.802 & 0.073 & $0.001^{*}$ & $0.658-0.946$ & - \\
Respiratory & 0.850 & 0.067 & $<0.001^{*}$ & $0.718-0.982$ & - \\
Coagulation & 0.829 & 0.069 & $<0.001^{*}$ & $0.694-0.965$ & -- \\
Hepatic & 0.772 & 0.081 & $0.003^{*}$ & $0.613-0.930$ & -- \\
Cardiovascular & 0.906 & 0.047 & $<0.001^{*}$ & $0.814-0.997$ & $\geq 2.0$ \\
Neurologic & 0.869 & 0.060 & $<0.001^{*}$ & $0.752-0.986$ & -- \\
Renal & 0.920 & 0.039 & $<0.001^{*}$ & $0.843-0.997$ & $\geq 2.0$ \\
Total pSOFA & 0.821 & 0.069 & $<0.001^{*}$ & $0.687-0.956$ & -- \\
\hline
\end{tabular}

AUC: Area under curve, SE: Standard error, CI: Confidence interval, *significant

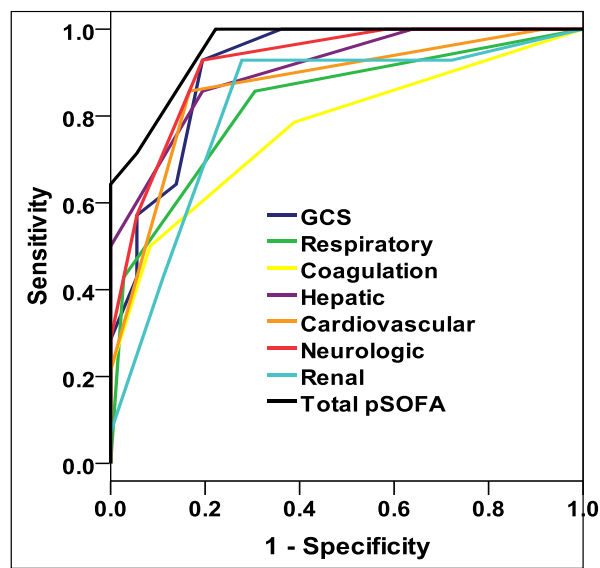

Fig [3] ROC curve for GCS and pSOFA scores in prediction of death

Table [4] Diagnostic characteristics of suggested cut off points in prediction of death 


\begin{tabular}{|c|c|c|c|c|}
\hline Characters & Value & $95 \% \mathrm{CI}$ & Value & $95 \% \mathrm{CI}$ \\
\hline & \multicolumn{2}{|c|}{ GCS $\leq 13.0$} & \multicolumn{2}{|c|}{ Hepatic score $\geq 2.0$} \\
\hline Sensitivity & $100.0 \%$ & $76.8 \%-100.0 \%$ & $85.7 \%$ & $57.2 \%-98.2 \%$ \\
\hline Specificity & $63.9 \%$ & $46.2 \%-79.2 \%$ & $80.6 \%$ & $64.0 \%-91.8 \%$ \\
\hline DA & $74.0 \%$ & $59.7 \%-85.4 \%$ & $82.0 \%$ & $68.6 \%-91.4 \%$ \\
\hline Youden's index & $63.9 \%$ & $\underline{48.2 \%-79.6 \%}$ & $\underline{66.3 \%}$ & $\underline{43.8 \%-88.7 \%}$ \\
\hline PPV & $51.9 \%$ & $31.9 \%-71.3 \%$ & $63.2 \%$ & $38.4 \%-83.7 \%$ \\
\hline \multirow[t]{2}{*}{ NPV } & $100.0 \%$ & $85.2 \%-100.0 \%$ & $93.5 \%$ & $78.6 \%-99.2 \%$ \\
\hline & \multicolumn{2}{|c|}{ Neurologic score $\geq \mathbf{2 . 0}$} & \multicolumn{2}{|c|}{ Total pSOFAscore $\geq 9.0$} \\
\hline Sensitivity & $92.9 \%$ & $66.1 \%-99.8 \%$ & $100.0 \%$ & $76.8 \%-100.0 \%$ \\
\hline Specificity & $80.6 \%$ & $64.0 \%-91.8 \%$ & $77.8 \%$ & $60.8 \%-89.9 \%$ \\
\hline DA & $84.0 \%$ & $70.9 \%-92.8 \%$ & $84.0 \%$ & $70.9 \%-92.8 \%$ \\
\hline Youden's index & $73.4 \%$ & $54.7 \%-92.1 \%$ & $77.8 \%$ & $64.2 \%-91.4 \%$ \\
\hline PPV & $65.0 \%$ & $40.8 \%-84.6 \%$ & $63.6 \%$ & $40.7 \%-82.8 \%$ \\
\hline NPV & $96.7 \%$ & $82.8 \%-99.9 \%$ & $100.0 \%$ & $87.7 \%-100.0 \%$ \\
\hline
\end{tabular}

CI: Confidence interval, YI: Youden's index, DA: Diagnostic accuracy, PPV: Positive Predictive value, NPV: Negative Predictive value

\section{Discussion}

Our study was conducted at the pediatric intensive care unit, Pediatric Hospital, Benha University and Benha children hospital. Fifty critically ill patients were included in our study.

In the current study we found that sex was almost equal among the studied cases. This is in accordance with the study done by [14] who made prospective study which was conducted in the Beijing Chao-yang Hospital . From December 2011 to October 2012, Patients were classified at the time of enrollment as having systemic inflammatory response syndrome [SIRS], sepsis, severe sepsis and septic shock, according to ACCP/SCCM criteria [13]. He found that, among 859 patients in the ED and 100 healthy controls were enrolled in his study. No significant differences were found in sex and correlative diseases among the five groups [SIRS, sepsis, severe sepsis, septic shock, and control groups].

While [10] found significant male predominance in PICU population was noticeable. For almost 3 boys admitted there only one girl [male to female ratio $=3: 1$ ] . This is attributed that to the social bias still prevailing against the girl child in India.

Regarding general characters of the study population, the mean age of our patients was 2.6 years.This agrees with [17] who aimed to analyze the epidemiologic patterns of pediatric critically ill patients presenting to the pediatric intensive care unit [PICU] and the etiologies of PICU admission of different age groups in a tertiary medical Hospital, in Cairo, from 2011 to 2012. He noticed that children younger than 5 years of age were the vulnerable age group representing the majority of admitted patients to PICU. Winter [November and December] was the season of the highest PICU admission reflecting the possibility of droplet infection predominance [respiratory manifestations].

Our study shows that, regarding etiology of the studied cases. septic shock and respiratory failure were the most frequent etiologies. This cause of increase the risk of chest infections, include environmental factors, genetic susceptibility, ethnic causes. [3].

This agrees with [3] who found chest infection was the most common cause for admission in PICU.This agrees also with [22] who found that, diseases of the respiratory system was the major cause for admission in PICU.

This may be explained by young children are likely to have compromised immunity because of the associated undernutrition and inadequate zinc intake. Environmental factors, such as living in crowded homes and exposure to parental smoking or indoor air pollution, might also have a role to play in increasing children's susceptibility to pneumonia. [9].

In the present study, mean value of $\mathrm{Hb}$ was low and a high significant decrease in platelets count among cases. These results agreed with [19] who found that, mean value of $\mathrm{Hb}$ was significantly lower among septic group than control group.This is also consistent with other studies [4] who found that The platelet count was significantly lower between cases than control.

Thrombocytopenia may be attributed to bone marrow depression, consumption coagulopathy, platelet sequestration, or a combination of these processes. [4].

In the current study, the overall mortality rate was $28 \%$, but was $6.8 \%$ in the [7] study, $16.6 \%$ in [12] study, and $44.5 \%$ in the [11] study. Differences in severity of illness and the quality of care between ICUs may explain these discrepancies. 
Our study showed that, GCS was significantly lower among died cases than among lived cases.

This is in agreement with [18] who found that, The nonsurvivors showed significantly lower values for GCS than survivors .

Our study showed that, platelets was significantly lower among died cases than lived cases. This is in agreement with [21].

Our study showed that, the value of pSOFA score was significantly higher among non-survived than survived cases [13.5,5.5 respectively]. This agrees with [6] who aimed to compare SOFA and PELOD scoring systems as a mortality predictor at pediatric intensive care unit. A Prospective, Hospital based study. Pediatric Intensive Care Unit, G.R. Medical College, Gwalior Critically ill children admitted to Pediatric Intensive Care Unit. After recruitment in the study, patients were followed until they were discharged from PICU or deceased .They found mean SOFA in nonsurvivors was 30.44 and in survivors was $13.90[\mathrm{p}<0.001]$.This is in agreement also with [5] who analyzed the SOFA scores and found that SOFA was high in non survivors as compared to survivors $[\mathrm{p}<0.001]$.

SOFA Score can reliably describe the prognosis in children, regular and repeated scoring may be more helpful in identifying the categories of patient at major risk of prolonged stay or death. Our study reveals that SOFA at 72 hours score is statistically strong enough to prognosticate risk of mortality in PICU. It can correlate well to mortality as PELOD can.

The SOFA score can be used as a reliable prognostic predictor of mortality among PICU patients [8].

This is in agreement with [18] who found that, the mean SOFA score was significantly lower in survivors compared to nonsurvivors.

This study showed that, Total pSOFA $\geq 9.0$ had highest diagnostic characteristics in prediction of death.This agrees with [2] who emphasized on the use of SOFA score as a prognostic indicator in critically ill children as variables measured are easily available and routinely measured in PICU while PELOD score is cumbersome.

[16] who adapted and validated an age-adjusted version of the SOFA score for pediatric patients [pSOFA]. The pSOFA score showed excellent discrimination for in-hospital mortality in a general PICU population, which was comparable to or better than the performance of other common pediatric organ dysfunction scores.

This study showed that, pSOFA, GCS, hepatic score, neurologic score and total score had significant high diagnostic performance in predicting death. Creatinine, total bilirubin, respiratory score, cardiovascular score and renal score had significant moderate diagnostic performance in predicting death. $\mathrm{PaO} 2: \mathrm{FiO} 2$, platelets, coagulation had significant low diagnostic performance in predicting death. Other variables had no significant diagnostic performance in predicting death.

The best cut-off score for SOFA in the [1] study was also 4.5, and the $\mathrm{AUC}=0.731$, sensitivity $=73 \%, \quad$ specificity $=68 \%, \quad$ NPV [Negative Predictive Value] $=86 \%$, and PPV [Positive Predictive Value] $=47 \%$ was similar to our findings. The best cut-off score for GCS in the [15] study was 4.5, which is lower than our finding; they assessed the predictive value of GCS among 60 brain-injured adult patients. The $\mathrm{AUC}=0.947$, sensitivity $=95.3 \%$, specificity $=82.4 \%, \quad \mathrm{NPV}=87.5 \%, \quad$ and PPV $=93.2 \%$ also showed that the GCS had a better performance in that different setting.

\section{Conclusion}

Pediatric SOFA score [pSOFA] score can be used as a reliable prognostic predictor of mortality among PICU patients.

\section{References}

[1] G.P.Castelli, C.Pognani, M.Meisner, Procalcitonin and $\mathrm{C}$-reactive protein during systemic inflammatory response syndrome, sepsis and organ dysfunction. Crit Care, vol.8(4),pp.R234,2004

[2] D.G.Craig, T.W.Reid, K.G.Martin, J.S.Davidson, The systemic inflammatory response syndrome and sequential organ failure assessment scores are effective triage markers following paracetamol overdose. Aliment Pharmacol Ther,Vol.(34),pp.21928,2011.

[3] H.A.El-Kinany, A.A.Mahfouz, L.E.Abd ElFattah, Impact of pre-pediatric ICU management on prognosis of sepsis and septic shock at Alexandria University Children's Hospital. Alex J Pediatr [serial online] Dec, vol.(24),pp.31:14-21,2018.

[4] A.M.El-Mazary, M.F.Afifi, S.E.Maher, M. Bassyouni, Neutrophil CD64 in early-onset neonatal sepsis. Egyptian Journal of Pediatric Allergy and Immunology, vol.(81),pp.1925,2010.

[5] F.L.Ferreira, D.P.Bota, A.Bross, C.Mélot , Serial evaluation of the SOFA score to predict outcome in critically ill patients. JAMA.vol.286(14),pp.1754-1758,2001.

[6] P.Gogia, S.Koreti, G.Patel : SOFA [sequential organ failure assessment] and PELOD [pediatric logistic organ dysfunction]. Sch J App Med Sci, vol.3(4A),pp.1645-1648,2015.

[7] J.Jentzer, D.Murphree, K.Banaei-Kashani , 465: predictive value of the sofa score for inpatient mortality across different Icu populations. Crit Care Med, vol.46(1),pp.216,2018. 
[8] A.E.Jones, S.Trzeciak, J.A.Kline, The sequential organ failure assessment score for predicting outcome in patients with severe sepsis and evidence of hypoperfusion at the time of emergency department presentation. Crit Care Med.vol.37(5),pp.1649-54,2009

[9] R.Kc, S.D.Shukla, S.S.Gautam, P.M.Hansbro , The role of environmental exposure to noncigarette smoke in lung disease. Clinical and translational medicine, vol.7(1),pp.39,2018.

[10] P.Khilnani, D.Sarma, R.Singh, R.Uttam, Demographic profile and outcome analysis of a tertiary level pediatric intensive care unit. Indian J Pediatr, vol.71 (7),pp.587-91,2004

[11] B.Khwannimit, R.Bhurayanontachai, V.Vattanavanit Comparison of the performance of SOFA, qSOFA and SIRS for predicting mortality and organ failure among sepsis patients admitted to the intensive care unit in a middle-income country. J Crit Care vol.(44),pp.156-160,2018.

[12] M.A.Lee, K.K.Choi, B.Yu, J.J.Park, Acute physiology and chronic health evaluation II score and sequential organ failure assessment score as predictors for severe trauma patients in the intensive care unit. Crit Care Med vol.32(4),pp.340-346,2017.

[13] M.M.Levy, M.P.Fink, J.C.Marshall, SCCM/ESICM/ACCP/ATS/SIS International Sepsis Definitions Conference". Crit Care Med; vol.31(4),pp.1250-1256,2003.

[14] B.Liu , Y.Chen, Q.Yin, Diagnostic value and Prognostic evaluation of presepsin for sepsis in an emergency department. Critical care; vol.(17), pp.244,2013.

[15] M.Mahdian, M.R.Fazel, E.Fakharian, H.Akbari, S.Mahdian, Cerebral state index versus Glasgow coma scale as a predictor for in-hospital mortality in brain-injured patients. Chin J Traumatol vol.17(4),pp.220-224,2014.
[16] T.J.Matics, L.N.Sanchez-Pinto: Adaptation and Validation of a Pediatric Sequential Organ Failure Assessment Score and Evaluation of the Sepsis-3 Definitions in Critically Ill Children. JAMA Pediatrics, vol.(171)(10),pp.72352,2017.

[17] H.I.Rady. Profile of patients admitted to pediatric intensive care unit, Cairo University Hospital, 1-year study. Ain-Shams J Anaesthesiol [serial online]vol.(12),pp.7:500-3, 2014

[18] J.Ramazani, M.Hosseini, Prediction of ICU mortality in critically ill children. Med Klin Intensivmed, vol.(2),pp. 136,2018.

[19]T.Shozushima, G.Takahashi, N.Matsumoto: Usefulness of presepsin [sCD14 ST] measurements as a marker for the diagnosis and severity of sepsis that satisfied diagnostic criteria of systemic inflammatory response syndrome. Journal of Infection and Chemotherapy;vol.17(6),pp.764-769n,2011.

[20] J.A.Tantalean, R.J.Leon, A.A.Santos, E.Sanchez: Multiple organ dysfunction syndrome in children. Pediatr Crit Care Med.vol.(42),pp.181185,2003

[21] R.S.Watson, S.Crow, M.E.Hartman, J.Lacroix, : Epidemiology and Outcomes of Pediatric Multiple Organ Dysfunction Syndrome. Pediatric critical care medicine : a journal of the Society of Critical Care Medicine and the World Federation of Pediatric Intensive and Critical Care Societies, 18[3_suppl Suppl 1], S4-S16. doi:vol.(10),pp.1097,2017.

[22]W.C.Yang, Y.R.Lin, L.L.Zhao, Y.K.Wu: Epidemiology of pediatric critically-ill patients presenting to the pediatric emergency department. Klin Padiatr;vol.(225);pp.1823,2013 